\title{
Daily Life with Type 1 Diabetes from the Perspectives of Young Adults and Their Close Relatives
}

\author{
Åsa Carlsund, Siv Söderberg \\ Department of Nursing Sciences, Mid-Sweden University, Östersund, Sweden \\ Email address: \\ asa.carlsund@miun.se (A. Carlsund), siv.soderberg@miun.se (S. Soderberg)
}

To cite this article:

Åsa Carlsund, Siv Söderberg. Daily Life with Type 1 Diabetes from the Perspectives of Young Adults and Their Close Relatives. American Journal of Nursing Science. Vol. 7, No. 4, 2018, pp. 115-120. doi: 10.11648/j.ajns.20180704.11

Received: May 2, 2018; Accepted: May 22, 2018; Published: June 13, 2018

\begin{abstract}
The aim of this study was to enhance a deeper understanding of daily life as experienced by young adults with Type 1 Diabetes and their close relatives. Young adulthood is commonly considered as an amendment to adult roles. Increased responsibility, such as a long-term illness in young adulthood, might lead to increased stress and anxiety. Type 1 Diabetes involves large obligations related to self-care, and close relatives might play an important role in managing daily life. A hermeneutic study involving interviews with a narrative approach with couples. The hermeneutic analysis revealed that T1D is always unconditionally present in daily life for young adults and their close relatives. Close relatives are important supporters, they have an understanding based on sharing daily life with the young adults with T1D. Young adults and their close relatives highlighted the experiences of being questioned, which in turn threatens the young adults' integrity.
\end{abstract}

Keywords: Close Relatives, Couples, Hermeneutic, Type 1 Diabetes, Young Adults

\section{Introduction}

Living with a long-term illness such as Type 1 Diabetes (T1D) means a variety of changes and consequences in one's everyday life [1,2]. Type 1 Diabetes is a common illness, as about 387 million people live with the condition worldwide $[3,4]$ In Sweden, almost 40,000 adults with diabetes were registered in 2016, approximately 10,000 of whom were young adults [5]. Sweden has one of the highest levels of prevalence of T1D in the world, second only to Finland [6]. In $\mathrm{T} 1 \mathrm{D}$, an autoimmune process destructs the insulinproducing beta cells of the pancreas, and insulin must be provided through alternative means $[7,8]$. One of the most important treatment goals for people with T1D is to strive to attain as normal of blood glucose levels as possible.

Young adulthood in combination with T1D involves numerous challenges and concerns, beyond those experienced by most individuals in this age group $[9,10]$. This period of life is commonly considered as a stepwise separation from parents and an amendment to adult roles [11, 12]. However, the increased responsibility in young adulthood might, in turn lead to increased stress and anxiety $[12,13]$. Marshall et al. (2009) showed that parents of children with T1D needed to accept, trust, and support their children's ability to make their own decisions related to the T1D [14]. Furthermore, Abdoli et al. (2017) stated that young adults with T1D exhibited daily struggles living with their illness, attempting to grow and move into adult roles while taking complete responsibility of their diabetes management [15].

Previous research $[16,17]$ has indicated that up to half of the young adults with T1D develop diabetes-related complications as they grow older, e.g., retinopathy, neuropathy, and hypertension. Similarly, earlier studies [18, 19] have shown that young adults with T1D have an improved mortality risk compared to the general population. As T1D involves several obligations related to self-care management and in many cases close relatives play an important role [20, 21].

To the best of our knowledge, there is a lack of studies on young adults living with T1D and their close relatives, including the individual and shared experiences of dealing with the long-term illness. Therefore, couples in our study consisted of a young adult with T1D and a close relative. Interviewing couples in naturally occurring pairs can contribute to the understanding of individual as well as 
shared perspectives on a certain topic [22, 23]. According to Benner and Wrubel (1989), understanding how people experience illness is vital for curing and healing [24]. Thus, the aim of this study was to enhance a deeper understanding of daily life as experienced by young adults with T1D and their close relatives.

\section{Materials and Methods}

\subsection{Design}

A qualitative design was used in order to enhance understanding of living with T1D. Interviews with a narrative approach were conducted. In order to gain in-depth information of daily life with T1D, the interview questions were constructed to cover different aspects experienced by young adults and their close relatives [25].

\subsection{Participants and Procedure}

Six young adults living with T1D and their close relatives (six women and six men) were recruited with a purposive sampling method. The participants were aged between 20 and 59 years $(\mathrm{md}=28)$. Eight participants had a high school educational level, and four had a university education. The criteria for participation was a diagnosis of T1D and speaking and understanding the Swedish language. The participants were recruited from in the middle of Sweden. A diabetic nurse at the hospital mediated contact with patients that fulfilled the inclusion criterion. Seventy invitation letters were sent to presumptuous participants, twelve returned prefilled answering letters, and were then contacted via telephone by the first author. The participants were recruited with help from a previous study performed by the authors.

\subsection{Interviews}

In order to move beyond the bounds of one person and grasp the experiences among the couples (young adults with T1D and their close relatives), data was collected through interviews with a narrative approach. The interviews lasted between 40 and 70 minutes $(\mathrm{md}=44)$. The couples were asked to narrate their experiences of daily living with T1D. In order to further understand the couple's mutual story, circular questions were posed, such as, "What do you think about what he/she just said?" and "Do you feel the same about what he/she just said?" The interviews were taperecorded, transcribed verbatim, and numbered from 1 to 6 to place quotations in the results section. To enable identification of the quotations by the young adults with T1D, the letter "a" was placed after the quotation number; for the close relatives, the letter " $b$ " was placed after the number, e.g., 1a, 1b. In accordance with the couples' wishes, the interviews took place in a quiet room at the researchers' workplace.

\subsection{Data Analysis}

To reach a deeper understanding of daily life for young adults with T1D and their close relatives, the Gadamerianbased research method outline by Fleming et al. (2003) was used in this study [26]. This method is grounded on Gadamer's philosophical hermeneutics with a focus on understanding and interpretation [27]. Gadamer believed that understanding begins with a question, as it opens up different horizons of understanding. Fleming et al. (2003) introduced a five-step process for data analysis. In the first step, the research question is identified; in the second step, the researcher's pre-understanding is recognized [26]. In order to reach and transcend the understanding of the phenomenon, the researcher's pre-understanding is essential, according to Gadamer (1994). The third step consists of gaining understanding through dialogue with the participants; in this study, this is accomplished through interviews with the young adults with T1D and their close relatives. The next step consists of gaining understanding through dialogue with the interview text, i.e., identifying meaning units of the interviews that correspond to the aim of the study. In this study, the analysis starts with reading the interview texts several times to reach a sense of the whole. Therefore, the research question and the researcher's pre-understanding were vital. The next step involved a dialogue with the interview text, which means identifying meaning units and comparing them based on similarities and differences. The last step is establishing trustworthiness.

Trustworthiness

Fleming et al. (2003) stated that a Gadamerian researcher has the responsibility to present the research process in a clear way [26]. In this study, credibility, confirmability, and truthfulness are qualities of trustworthiness that are reflected. Credibility was established by the presentation of quotations from the interviews, which give the reader a possibility to judge the credibility of this study. Confirmability was established through returning to the interview texts during the research process. According to Gadamer (1994), there is no universal truth; therefore, understanding can only be recognized when an agreement between the parts and the whole of the interview texts is achieved. In this study, the pre-understanding as registered nurses and researchers in nursing may affect our understanding and interpretation of data [27]. The interpretation that is present in this study is not a single truth, instead it is the most probable interpretation constructed on preunderstanding and analysis of the interview texts.

\subsection{Ethical Considerations}

Participants were informed about the nature of the study, confidentiality, and the anonymous results presentation. Written informed consent was obtained from the participants. Ethical approval was obtained from the Regional Ethics Review Board, Umeå, Sweden (DNR 2017/79-31M).

\section{Results}

The analysis revealed the following four themes: an always present actuator, possessed with knowledge, a shared 
understanding, and a hopeful future. The themes are presented below with citations from the interviews.

\section{An always present actuator}

Couples described that daily life gave the impression of an always present actuator, i.e. the T1D always unconditionally were present and they all found different ways of handling ups and downs. They described that they tried to live as normally as possible. Times to times it happened that their plans needed to change, related to low or high blood glucose or other issues caused by the illness. "It has sometimes happened when she goes low...We would have to change plans of going out for dinner and eat a late dinner at home instead. But that's the way it is, nothing to feel sad about" (2b). Handling low blood glucose was described as the most common cause that influenced daily life through, for example, anxiety, preparation, and responsibility for the partner. The participants with T1D described that it was a little embarrassing to tell about low blood glucose, instead they could feel bad without saying something to for example, their co-workers. "I went low, looked at the candy bowl, felt like I dribbled, which I probably didn't.... My mind screamed sugar, sugar...I knew, just knew I was in urgent need of sugar. But I was too embarrassed to tell him..." (4a). They expressed that they constantly were afraid of passing out in public, not remembering what had happened, and experiencing completely panic, even screaming without being aware. Participants described mood swings with low and high blood glucose as embarrassing, annoying, and difficult both for them and their close relatives. Close relatives expressed that they had been afraid of the anger related to low blood glucose. "In the beginning, I didn't know what was what. Is he in a bad mood, or is it his illness? Roars from another room could make me anxious. Now, I've learned..." (5b).

Participants with T1D described that they did not want to burden their surroundings, while the partners described that, for them, helping, relieving, and supporting were natural. They wanted to do the little things they could and give credit to their loved ones with T1D for their always present struggle, as they can never take a leave from their illness. "I wish I could relieve the burden for a while, like a weekend or so" (5b). The close relatives described a constant presence of concern when they were not at the same place as their loved ones with T1D; they would call, send text messages, and check the sensor to alleviate their worries. "I know he's kind of confused and I'm the worrying kind, but I need to know where he is and how he is..." (1b).

High blood glucose was another concern for close relatives, as mood and anger can fluctuate correspondingly for those with T1D. The relatives explained that, when this occurred, especially at the beginning of their relationship, it often led to unhappiness, disturbances, and conflicts. The close relatives described that as when time went by, they learned more and understood the difference between common anger and anger related to T1D. "Now I've learned... and sometimes, I just take the scanner, make a scan, and show it to her face...Without saying anything...aha, high...” (1b).
Close relatives expressed worry for what high blood glucose could do to the person with T1D (i.e., problems with eyes, kidneys, and life in the future). Participants with T1D described that they had an ongoing worry that their condition will worsen, but they refrained from talking about this concern with their relatives "Some things I choose to keep to myself... They are tough thoughts, and I really don't want to unnecessarily frighten him" (3a).

Possessed with knowledge

Couples expressed that they believe that knowledge about T1D was valuable and necessary in order to talk, discuss, and be available in daily life. Through knowledge, they could find different solutions together, which was a way to accept the situation as it is. "This is the way it works for us, mostly so, to say...How does it work for others? I haven't the slightest idea" (1b). Close relatives described that they had to learn over time, and that nothing was clear from the start. They had learned what worked best, for example, with low blood glucose for their loved ones with T1D. "In the beginning, I didn't really know what to do. Now, I know when it's time for raisins, a sandwich, and so on..." (3b).

Couples described that they often encounter ignorance by healthcare personnel or other people who do not know the difference between diverse types of diabetes. At the same time, the close relatives admitted that they recognized themselves from before, when they did not have any knowledge about T1D. They described that they had not knowledge about howthe complications, time, and engagement involved in living with T1D and that it demands much time and engagement. "I'd probably do best in keeping my mouth shut. Before I got close to diabetes, I didn't know the difference... I could never figure out why they needed sugar, that their illness is derived from high blood sugar..." (5b). Participants with T1D described that, occasionally, it can be hard to explain and be questioned about, for example, taking injections or consuming certain foods, for example, food with sugar. "I know from the bottom of my heart that it's my choice to explain or not, but sometimes I get so sick and tired...so I say nothing at all" (1a). Close relatives expressed this situation as frustrating and violating, as the person with T1D have to explain, defend, and, in some cases, argue about how they manage their own illness. Close relatives described that some people believe that they know more than the person with T1D, which can be both strenuous and irritating. "Sometimes, when I come home from work, I'm still angry from a discussion we had at lunch, some idiot co-worker told me how we should live a better, healthier life, with no carbs..." (5b). Participants with T1D agreed that it was difficult when others talk about how the condition should be handled.

\section{A shared understanding}

Couples described having a person to share things with concerning daily life with T1D as a nice and safe feeling "He is my everything. I can safely go to sleep and he will watch my back... 100 percent" (2a). They expressed the shared responsibility, anxiety, and reflections as something that strengthen their relationship. The support was pictured in 
different ways, for example, a partner showing interest, wanting to learn, and searching for knowledge and information on his or her own. "Sometimes, you show me the latest news from the Internet" (6a). For the person with T1D, it was important that their close relatives were open to discussions about, for example, insulin dosage based on carbohydrates or blood glucose, scanning blood glucose levels at night, or accompanying them to meetings with physicians or other meetings related to T1D. For the close relatives, it was important to be knowledgeable about how different aids function. First and foremost, it was of the utmost importance that the close relatives had a deep understanding about living with T1D. Couples described that only a few people were close enough and given the trust to be this source of support. "Not many people are trusted with such responsibilities. At first, I knew nothing, but now, I feel proud" (3b). Most participants with T1D expressed a wish to manage the illness but described gratefulness and contentment to have close relatives to trust and the opportunity to hand over to someone else. Close relatives described that, for them, showing consideration and being as supportive as possible had become natural, and that they had learned to differentiate when it was time to help or best not to intervene. "I check out for new updates or comments on social media. After scanning them, I know if it's time for a talk or not..." (6b).

\section{A hopeful future}

Couples described positive feelings when thinking about the future. They expressed hope that research about devices and treatments would offer results to simplify everyday life or, most of all, a cure for T1D. They believed that a cure would not appear during their lifetimes, they expressed hope for devices that would help persons with T1D to live as seamlessly as possible. They hope stated that they desire to be parents in the future, and hope that the illness would not affect the child. However, were the child to be affected by T1D, they said that, as parents, they would be knowledgeable about functioning in everyday life and could help the child. "I don't hope for a child with diabetes, or any illness, for that matter, but if that is so, I know we could handle it and become proper parents" (2a). Some described that they did not want to think about the future, and only wished to live in the present. "I'm so young, you know. I don't want to think about the future...I want to have fun, get drunk, have parties, and live life" (4a). Participants with T1D stated that they worry about the future, about what could possibly happen and risks for complications later in life. "I constantly think of things that might happen in the future. I don't want to think about it, but I constantly do... and blame myself for the high values" (4a).

\section{Discussion}

The aim of this study was to enhance a deeper understanding of daily life as experienced by young adults with T1D and their close relatives. The results show that T1D is always unconditionally present in daily life for the participants. They described trying to live as normally as possible. Toombs (1992) highlighted that living with a longterm illness (such as T1D) means that the ability to take certain aspects of daily living for granted is interrupted, and that the experience of illness as a fundamental loss of wholeness manifests itself in various ways [1]. This viewpoint seems relevant for the participants in this study, as the results show that T1D is seen as an always present actuator.

People living with T1D described mood swings related to low or high blood glucose as problematic and difficult both for themselves and their close relatives. However, the most exemplified concerns were the fear of passing out in public due to low blood glucose and losing control over the situation. As several prior studies have reported women as well as men being afraid of low blood glucose [28-30], this can be seen as another factor that can be taken for granted in daily life. To reduce this fear, analyses, actions, and perspectives from both society and health care personnel are needed [31].

The results show that close relatives expressed having experienced incidents during which they felt afraid of the anger related to low as well as high blood glucose, especially in the beginning of the relationship. However, as time went by, they learned more about the difference between common anger and anger related to low blood glucose. It has been previously shown that family involvement is of elevated importance for people living with long term illness, especially in urgent situations $[32,33]$. The results show that supportive and involved close relatives are an essential part of everyday life of young adults living with T1D, which is in direct contrast to the results of [34]. This means that support from close relatives can be seen as a tool, which highlights the importance of close relatives being knowledgeable about T1D for understanding related to offering support. As shown in earlier studies, close relatives want to help, relieve, and support their loved ones $[35,36]$.

A longitudinal study showed that supportive relationships with close relatives have a profound impact on health behaviors and mental health for young adults with and without T1D [21]. This corresponds well to the results, as phone calls, text messages, and scan checks are everyday life issues and a constant presence of concern, as described by the close relatives.

Couples expressed that they believe that knowledge about the illness was valuable and necessary in order to talk, discuss, and be available in daily life with T1D. The present results show that healthcare personnel and people in society often do not know about the different types of diabetic conditions. Lack of knowledge and indifference towards T1D are common views in society [20,37].

Participants with T1D did not like being questioned when taking injections or consuming certain foods, for example, food with sugar. Close relatives meant stated that, when the person with T1D had to explain, defend, and, in some cases, argue about the way they manage their illness, it was seen as violating, as some people believe that they know more that 
the person with T1D. This questioning can demonstrate a lack of integrity and respect towards the individuals with T1D. According to Weil (1994), respect is a fundamental quality in any encounter between people [38]. In this study, shared responsibility and reflections in togetherness were described to strengthen the couples' relationships, often through the mutual understanding about living with T1D. The young adults and their close relatives encounter each other with a shared understanding, which is an important support for young adults with T1D [39]. Participants with T1D expressed they wanted to manage the illness, but they were also grateful and content to have trusted close relatives.

Couples described positive feelings and worries about the future. They worried about what could possibly happen, such as risks for complications later in life. Participants with T1D had an ongoing worry regarding getting worse and not being able to take care of themselves. Furthermore, these worries were not shared with their relatives.

Despite these concerns, the couples in this study hope that future research can simplify everyday life and, hopefully, lead to a cure for T1D. Grady (1973) designated hope as an affirmation by a person that life as a value [40]. Abdoli (2017) showed that young adults with T1D hope for a better tomorrow, including a cure for diabetes and more advanced technology [15].

\section{Conclusion}

This study shows how young adults with T1D strive for a normal daily life, i.e., a daily life that can be taken for granted by those who do not have experience with T1D. They live daily life with an always present actuator, i.e., T1D. Their close relatives are important supporters, as they have an understanding based on the knowledge obtained by sharing daily life with the young adults with T1D. Both the young adults and their close relatives highlighted the experiences of being questioned, something that threatens the young adults' integrity. Despite worries about the future, a hope was salient in their expressions about daily life with T1D. A hope for a cure or treatment that simplified daily life with T1D was present in their narrations.

\section{Acknowledgements}

Gratitude to the participating couples.

\section{Conflict of Interest}

The authors declare that they have no competing interests.

\section{References}

[1] Toombs SK. The meaning of illness: A phenomenological account of the difference perspective of physician and patient. I: Spicker HTEJ, red. Philosophy and medicine. Indiana University Press: Bloomington and Indianapolis; 1992. s. 324.
[2] Charmaz K. Loss of self: a fundamental form of suffering in the chronically ill. Sociol. Health Illn. 1983; 5 (2):168-95.

[3] World Health Organisation. First global report on diabetes. 2016.

[4] You WP, Henneberg M. Type 1 diabetes prevalence increasing globally and regionally: the role of natural selection and life expectancy at birth. BMJ Open Diabetes Res Care 2016; 4 (1): $\mathrm{e} 000161$.

[5] Swedish National Diabetes Register. Annual Report,. 2016.

[6] Berhan Y, Waernbaum I, Lind T, Mollsten A, Dahlquist G. Thirty years of prospective nationwide incidence of childhood type 1 diabetes: the accelerating increase by time tends to level off in Sweden. Diabetes 2011; 60 (2):577-81.

[7] World Health Organisation. Diabetes. 2016.

[8] Daneman D. Type 1 diabetes. Lancet 2006; 367 (9513):84758 .

[9] Balfe M, Doyle F, Smith D, Sreenan S, Brugha R, Hevey D, et al. What's distressing about having type 1 diabetes? A qualitative study of young adults' perspectives. BMC Endocr Disord 2013; 13:25.

[10] Garvey KC, Wolpert HA. Identifying the Unique Needs of Transition Care for Young Adults With Type 1 Diabetes. Diabetes Spectrum 2011; 24 (1):22-5.

[11] Lindberg B, Söderberg S. Standing on their own feet: Experiences of young people living with Type 1 diabetes when entering adulthood - A qualitative study. International Diabetes Nursing 2015; 12 (3):79-85.

[12] Peters A, Laffel L. Diabetes care for emerging adults: recommendations for transition from pediatric to adult diabetes care system,. Diabetes Care 2011; 34 (11):2477-85.

[13] DeCoster VA. The emotions of adults with diabetes: a comparison across race. Soc. Work Health Care 2003; 36 (4):79-99.

[14] Marshall M, Carter B, Rose K, Brotherton A. Living with type 1 diabetes: perceptions of children and their parents. J. Clin. Nurs. 2009; 18 (12):1703-10.

[15] Abdoli S, Doosti Irani M, Hardy LR, Funnell M. A discussion paper on stigmatizing features of diabetes. Nursing Open 2018; 5 (2):113-9.

[16] Bryden KS, Dunger DB, Mayou RA, Peveler RC, Neil HA. Poor prognosis of young adults with type 1 diabetes: a longitudinal study. Diabetes Care 2003; 26 (4):1052-7.

[17] Vanstone M, Rewegan A, Brundisini F, Dejean D, Giacomini M. Patient Perspectives on Quality of Life With Uncontrolled Type 1 Diabetes Mellitus: A Systematic Review and Qualitative Meta-synthesis. Ont Health Technol Assess Ser 2015; 15 (17):1-29.

[18] Hanna KM. A framework for the youth with type 1 diabetes during the emerging adulthood transition. Nurs. Outlook 2012; 60 (6):401-10.

[19] Hirjaba M, Haggman-Laitila A, Pietila AM, Kangasniemi M. Patients have unwritten duties: experiences of patients with type 1 diabetes in health care. Health Expect 2015; 18 (6):3274-85. 
[20] Sparud-Lundin C, Ohrn I, Danielson E. Redefining relationships and identity in young adults with type 1 diabetes. J. Adv. Nurs. 2010; 66 (1):128-38.

[21] Helgeson VS, Palladino DK, Reynolds KA, Becker DJ, Escobar O, Siminerio L. Relationships and health among emerging adults with and without Type 1 diabetes. Health Psychol. 2014; 33 (10):1125-33.

[22] Morris RL, Kennedy A, Sanders C. Evolving 'self'management: exploring the role of social network typologies on individual long-term condition management. Health Expect 2016; 19 (5):1044-61.

[23] Bülow PH. Sharing Experiences of Contested Illness by Storytelling. Discourse \& Society 2004; 15 (1):33-53.

[24] Benner P, \& Wrubel, J.. The primacy of caring: Stress, and coping in health and illness.. Addison-Wesley Publishing Company, California,; 1989.

[25] Polit DF, Beck CT. Nursing research: Generating and assessing evidence for nurse practice. Philadelphia, USA: Lippincott Wiliams \& Wilkins.; 2016.

[26] Fleming V, Gaidys U, Robb Y. Hermeneutic research in nursing: developing a Gadamerian-based research method. Nurs. Inq. 2003; 10 (2):113-20.

[27] Gadamer HG, Weinsheimer J, Marshall DG. Truth and Method. Sheed \& Ward; 1993.

[28] Gonder - Frederick LA, Fisher CD, Ritterband LM, Cox DJ, Hou L, DasGupta AA, et al. Predictors of fear of hypoglycemia in adolescents with type 1 diabetes and their parents. Pediatric Diabetes 2006; 7 (4):215-22.

[29] Anderbro T, Amsberg S, Adamson U, Bolinder J, Lins PE, Wredling R, et al. Fear of hypoglycaemia in adults with Type 1 diabetes. Diabet. Med. 2010; 27 (10):1151-8.

[30] Haugstvedt A, Wentzel-Larsen T, Aarflot M, Rokne B, Graue M. Assessing fear of hypoglycemia in a population-based study among parents of children with type 1 diabetes psychometric properties of the hypoglycemia fear survey parent version. BMC Endocrine Disorders 2015; 15:2.
[31] Martyn-Nemeth P, Schwarz Farabi S, Mihailescu D, Nemeth J, Quinn L. Fear of hypoglycemia in adults with type 1 diabetes: impact of therapeutic advances and strategies for prevention - a review. J. Diabetes Complications 2016; 30 (1):167-77.

[32] Gunn D, Mansell P. Glycaemic control and weight 7 years after Dose Adjustment For Normal Eating (DAFNE) structured education in Type 1 diabetes. Diabet. Med. 2012; 29 (6):807-12.

[33] Anderson BJ, Wolpert HA. A developmental perspective on the challenges of diabetes education and care during the young adult period. Patient Educ. Couns. 2004; 53 (3):347-52.

[34] Scholes C, Mandleco B, Roper S, Dearing K, Dyches T, Freeborn D. A qualitative study of young people's perspectives of living with type 1 diabetes: do perceptions vary by levels of metabolic control? J. Adv. Nurs. 2013; 69 (6):1235-47.

[35] Mackey ER, Hilliard, M. E., Berger, S. S., Streisand, R., Chen, R., \& Holmes, C.. Individual and family strengths: An examination of the relation to disease management and metabolic control in youth with type 1 diabetes. Families, Systems, \& Health 2011; 29 (4):314-26.

[36] Cahill E, Lewis LM, Barg FK, Bogner HR. "You Don't Want to Burden Them":Older Adults' Views on Family Involvement in Care. Journal of Family Nursing 2009; 15 (3):295-317.

[37] Hillege S, Beale B, McMaster R. Enhancing management of depression and type 1 diabetes in adolescents and young adults. Arch. Psychiatr. Nurs. 2011; 25 (6):e57-67.

[38] Weil S. Att slå rot (To be rooted).. Skellefteå, Sweden: Artos bokförlag; 1994.

[39] Soderberg S, Strand M, Haapala M, Lundman B. Living with a woman with fibromyalgia from the perspective of the husband. J. Adv. Nurs. 2003; 42 (2):143-50.

[40] Grady J. Marcel and hope-loyalty and person J. Br. Soc. Phenomenol. 1973; 4 (3):256-264. 